\title{
Giant Incident Photon-to-Current Conversion with Photoconductivity Gain on Nanostructured Bismuth Oxysulfide Photoelectrodes under Visible-Light Illumination
}

\author{
Evgeny A. Bondarenko, Eugene A. Streltsov,* Mikalai V. Malashchonak, \\ Alexander V. Mazanik, Anatoly I. Kulak, and Ekaterina V. Skorb*
}

Nanostructured layered bismuth oxysulfide films synthesized by chemical bath deposition reveal a giant incident photon-to-current conversion efficiency (IPCE). This study shows that surprisingly for the cathodic photocurrent in the photoreduction process, the IPCE reaches $\approx 2500 \%$ in aqueous solutions containing $\left[\mathrm{Fe}(\mathrm{CN})_{6}\right]^{3-}$. The giant IPCE is observed starting from a certain minimal oxidizer concentration $\left(c>10^{-3} \mathrm{M}\right.$ for $\left.\left[\mathrm{Fe}(\mathrm{CN})_{6}\right]^{3-}\right)$ and decreases nonlinearly with an increase of illumination intensity. Giant IPCE is determined by the decrease in resistivity of the bismuth oxysulfide film under illumination with photoconductivity gain, which provides the possibility of charge carriers from an external circuit to participate in the photoreduction process. Giant IPCE is observed not only in $\left[\mathrm{Fe}(\mathrm{CN})_{6}\right]^{3-}$ solutions, but also in electrolytes containing other photoelectron acceptors: $\mathrm{Fe}^{3+}, \mathrm{I}_{3}{ }^{-}$, quinone, $\mathrm{H}_{2} \mathrm{O}_{2}$. In all, solution-processed layered bismuth oxysulfide films offer large-area coverage, nontoxicity, low cost, and compatibility with a wide range of substrates. Abnormally high photoelectrochemical activity, as well as a band gap energy value favorable for efficient conversion of solar light (1.38 eV, direct optical transitions), proves the potential of bismuth oxysulfide photoelectrodes for a new generation of high-performance photoconverters.
E. A. Bondarenko, Prof. E. V. Skorb

Biomaterials

Max Planck Institute of Colloids and Interfaces

14424 Potsdam, Germany

E-mail: skorb@scamt.ru

E. A. Bondarenko, Prof. E. A. Streltsov, M. V. Malashchonak,

Prof. A. V. Mazanik

Chemistry Department

Belarusian State University

Nezalezhnastsi Av. 4, Minsk 220030, Belarus

E-mail: streltea@bsu.by

Prof. A. I. Kulak

Institute of General and Inorganic Chemistry

National Academy of Sciences of Belarus

Minsk 220072, Belarus

Prof. E. V. Skorb

Laboratory of Solution Chemistry of Advanced Materials

and Technologies (SCAMT)

ITMO University

St. Petersburg 197101, Russian Federation

DOI: 10.1002/adma.201702387
In recent years, considerable research interest has been focused on the study of bismuth semiconductor compounds: vanadate $\mathrm{BiVO}_{4},{ }^{[1-5]}$ oxyhalides $\mathrm{BiOHal}$ $(\mathrm{Hal}=\mathrm{I}, \mathrm{Cl}, \mathrm{Br}){ }^{[6-10]}$ sulfide $\mathrm{Bi}_{2} \mathrm{~S}_{3},{ }^{[11-15]}$ and oxysulfides. ${ }^{[16-23]}$ This is due to their attractive photocatalytic and photoelectrochemical properties, as well as the fact that bismuth is a nontoxic, inexpensive material. Moreover, as a high- $Z$ element, bismuth demonstrates a high attenuation of $\mathrm{X}$ - and $\gamma$-ray quanta, making promising the development of detectors based on its semiconductor compounds. ${ }^{[24,25]}$

The first bismuth oxysulfide $\mathrm{Bi}_{2} \mathrm{O}_{2} \mathrm{~S}$ reported in 1984 has the same crystalline structure as bismuth oxyhalides. ${ }^{[26]}$ Both classes of compounds have a layered structure, where the $\left[\mathrm{Bi}_{2} \mathrm{O}_{2}\right]$ layers alternate with the layers of halogenide or sulfide anions. ${ }^{[26]} \mathrm{Bi}_{2} \mathrm{O}_{2} \mathrm{~S}$ is a n-type semiconductor ${ }^{[16]}$ and provides attractive photoelectric properties (band gap reported as $1.5^{[16]}$ and $\left.1.12 \mathrm{eV}\right) .^{[17]}$

Recently synthesized bismuth oxysulfide $\mathrm{Bi}_{9} \mathrm{O}_{7.5} \mathrm{~S}_{6}$ also has a layered structure, which consists of alternatingly packed $\left[\mathrm{Bi}_{2} \mathrm{O}_{2}\right]$ and $\left[\mathrm{BiS}_{2}\right]$ layers held together by van der Waals interaction. The band gap energy $E_{\mathrm{g}}=1.27 \mathrm{eV}$ and direct optical transitions ${ }^{[18]}$ lend this semiconductor high perspectives for solar energy applications.

The band gap energy $E_{\mathrm{g}}=0.99 \mathrm{eV}$ (direct optical transitions $)^{[19]}$ of layered oxysulfide $\mathrm{Bi}_{2} \mathrm{OS}_{2}$ composed of alternating $\left[\mathrm{Bi}_{2} \mathrm{O}_{2}\right]$ and $\left[\mathrm{BiS}_{2}\right]$ layers has the lowest value among the known oxysulfides, even smaller than the band gap of bismuth sulfide $\left(E_{\mathrm{g}}=1.3 \mathrm{eV}\right){ }^{[20]}$

According to X-ray photoelectron spectroscopy (XPS), bismuth and sulfur atoms have an oxidation state of +3 and -2 , respectively, in semiconductor bismuth oxysulfides considered above. ${ }^{[16,18]}$ A fundamentally different situation is observed in $\mathrm{Bi}_{4} \mathrm{O}_{4} \mathrm{~S}_{3}$. It was found that $\mathrm{Bi}_{4} \mathrm{O}_{4} \mathrm{~S}_{3}$ formed by alternating $\left[\mathrm{Bi}_{2} \mathrm{O}_{2}\right],\left[\mathrm{BiS}_{2}\right]$, and $\left[\mathrm{SO}_{4}\right]$ layers possesses superconductivity at temperatures less than 4.4-8.6 K. ${ }^{[21-23]}$ Sulfur atoms have different oxidation states: -2 in $\left[\mathrm{BiS}_{2}\right]$ layers and +6 in $\left[\mathrm{SO}_{4}\right]$ ones. Oxidation states of bismuth atoms in this compound are +3 and +2.5 in $\left[\mathrm{Bi}_{2} \mathrm{O}_{2}\right]$ and $\left[\mathrm{Bi}_{2} \mathrm{~S}_{4}\right]$ layers, respectively. ${ }^{[17]} \mathrm{Bi}_{4} \mathrm{O}_{4} \mathrm{~S}_{3}$ can be considered as one of two stable forms of $\mathrm{Bi}_{4} \mathrm{O}_{4}\left(\mathrm{SO}_{4}\right)_{1-x} \mathrm{Bi}_{2} \mathrm{~S}_{4}$, 
where $x$ can be equal to 0 or 0.5 corresponding to the $\mathrm{Bi}_{6} \mathrm{O}_{8} \mathrm{~S}_{5}$ and $\mathrm{Bi}_{4} \mathrm{O}_{4} \mathrm{~S}_{3}$ formula units. Elemental ratios and basic properties of the known bismuth oxysulfides, $\mathrm{Bi}_{2} \mathrm{~S}_{3}$ and $\mathrm{Bi}_{2} \mathrm{O}_{3}$ are summarized in Figure S1 (Supporting Information).

The mentioned layered structure of bismuth oxysulfides suggests that variation in stacking of "building blocks" $\left(\left[\mathrm{Bi}_{2} \mathrm{O}_{2}\right]\right.$, $\left[\mathrm{BiS}_{2}\right]$, sulfur layers, etc.) can provide a possibility to synthesize new compounds. Band gap energy favorable for efficient solar energy conversion can be expected taking into account $E_{\mathrm{g}}$ values for bismuth oxide, bismuth sulfide, and known bismuth oxysulfides (Figure S1, Supporting Information).

Small diffusion length of the minority charge carriers in light absorbing material is known to be one of the limitations of photoelectrochemical energy conversion efficiency. Nanostructured photoelectrodes (arrays of nanotubes or nanorods, mesoporous films, as well as films formed by thin platelet-like crystals of nanoscale thickness) provide an attractive possibility to solve this problem. Indeed, a sufficient thickness of such nanostructured films allows efficient light harvesting, whereas a short diffusion distance for the minority carriers toward the electrolyte solution provides low recombination losses.

Photoelectrochemical and photocatalytic behavior of bismuth oxyhalides, bismuth orthovanadate, as well as bismuth sulfide $\mathrm{Bi}_{2} \mathrm{~S}_{3}$ has been investigated to date in details. ${ }^{[1-15]}$ The first studies of photoelectrochemical behavior of $\mathrm{Bi}_{2} \mathrm{O}_{2} \mathrm{~S}$ and $\mathrm{Bi}_{2} \mathrm{O}_{2} \mathrm{~S} / \mathrm{In}_{2} \mathrm{O}_{3}$ heterostructure have demonstrated the possibility to utilize them as n-type semiconductors; dye-modified $\mathrm{Bi}_{2} \mathrm{O}_{2} \mathrm{~S} / \mathrm{In}_{2} \mathrm{O}_{3}$ is perspective as water-splitting catalyst. ${ }^{[16]} \mathrm{Nev}$ ertheless, photoelectrochemistry of bismuth oxysulfides is at an early stage in general.

Previously studied oxysulfide compounds have been prepared in many cases by high-temperature solid-state synthesis. At the same time, there is a rapidly growing interest in the preparation of materials and devices for optoelectronics and solar energy harvesting using solution-based approaches due to their simplicity and low cost. ${ }^{[27]}$

In this work, chemical bath deposition (CBD) was used to produce bismuth oxysulfide films for the first time (Figure S2, Supporting Information). Surprisingly, we detected (Figure 1) unique photoelectrochemical behavior of the synthesized films, not shown before for any known this material. Incident photon-to-current conversion efficiency (IPCE or Y) known as a number of electrons passing in a circuit per one incident photon reaches up to $2500 \%$ for the cathodic photocurrent.

CBD grown bismuth oxysulfide films possess a highly-developed structure formed by the randomly oriented nanoplatelets (Figure 2a,b). Their lateral size is of several hundreds of nanometers, whereas the thickness is remarkably smaller (tens of nanometers). The layered shape of crystallites confirmed by transmission electron microscopy (TEM, Figure 2c) provides high surface-to-volume ratio and a short path for charge carriers scavenged by electrolyte. Selected area electron diffraction (SAED, inset in Figure 2c) and high resolution TEM (Figure 2d) point to crystallinity of the prepared films with hexagonal lattice symmetry (inset in Figure 2c).

Qualitative elemental composition analysis of the synthesized films performed with XPS (Figure 2g) and energy-dispersive X-ray spectroscopy (Figure S3, Supporting Information) demonstrates the presence of $\mathrm{Bi}, \mathrm{S}$, and $\mathrm{O}$. Chemical analysis (Figure S1, Supporting Information) has shown a bismuthto-sulfur molar ratio $\mathrm{Bi}: \mathrm{S}=1.11: 1$, which is an intermediate value compared to other known bismuth oxysulfides.

XPS studies demonstrate binding energies of 159.3 and $164.6 \mathrm{eV}$ for Bi $4 \mathrm{f}_{7 / 2}$ and $4 \mathrm{f}_{5 / 2}$ electrons, respectively (Figure S4, Supporting Information), which is close to values reported for $\mathrm{Bi}_{2} \mathrm{O}_{3}$ and corresponds to +3 oxidation state. ${ }^{[28]}$ Peaks at 225.7 and $232.5 \mathrm{eV}$ for S 2s electrons (Figure 2e) correspond to -2 and +6 oxidation states of sulfur, respectively. ${ }^{[29]}$ Ion etching of the films (etching depth $10 \mathrm{~nm}$ ) results in almost complete disappearance of the peak corresponding to the +6 oxidation state of sulfur (Figure $2 \mathrm{f}$ ) suggesting that $\mathrm{S}^{6+}$ ions are formed on the surface of the film due to oxidation of $\mathrm{S}^{2-}$ during ambient storage. Since sulfur atoms in the films have only -2 oxidation state, the simplest formula unit can be represented as $\mathrm{Bi}_{10} \mathrm{O}_{6} \mathrm{~S}_{9}$, which differs from the atomic composition of all presently known bismuth oxysulfides.

The positions of lines in X-ray diffraction (XRD) patterns of the synthesized compound (Figure $2 \mathrm{~h}$ ) differ from those for any

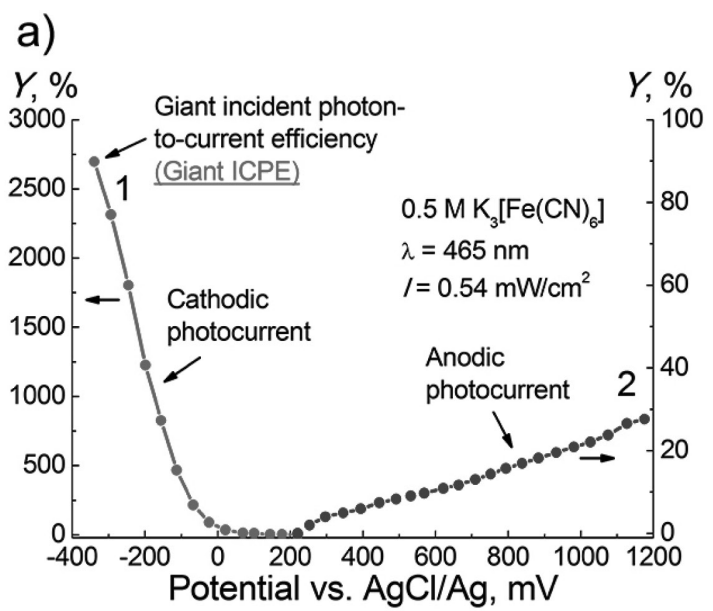

b)

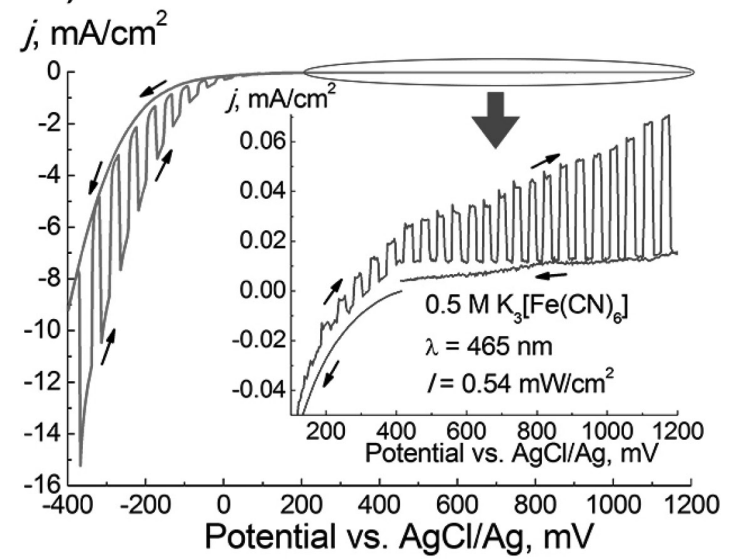

Figure 1. Photoelectrochemical behavior of bismuth oxysulfide films: a) dependence of IPCE on electrode potential for cathodic and anodic photocurrents derived from b) cyclic voltammogram with chopped illumination during anodic scan of electrode potential. 


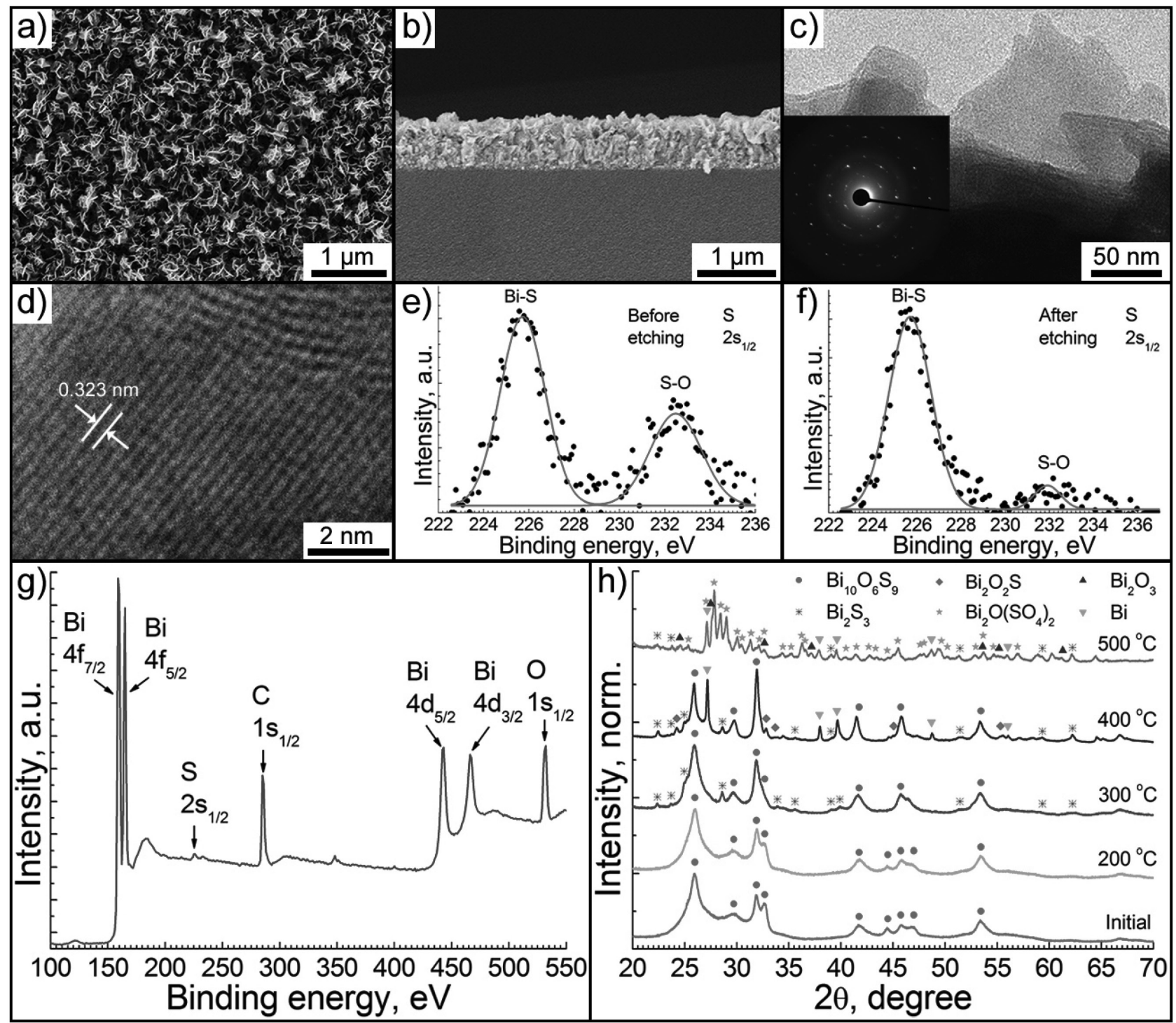

Figure 2. Structural characterization of bismuth oxysulfide: a) top-view and b) cross-sectional scanning electron microscopy (SEM) images of the film; c) transmission electron microscopy (TEM) image with selected area electron diffraction (SAED) pattern in inset; d) high-resolution transmission electron microscopy (HRTEM) image; e-g) X-ray photoelectron spectroscopy (XPS): e,f) S 2s high resolution spectra before and after surface etching; g) survey spectrum; and h) X-ray powder diffraction (XRD) of initial and heat treated samples.

oxysulfides described in the literature, which correlates with the chemical analysis results presented above. A large width of lines may originate from a high defect density in the films, a small thickness of the nanoplatelets and tensile/compressive strains due to their curvature (Figures 2a,d), which impedes a reliable identification of crystalline structure. The films were heat treated in Ar atmosphere to improve their crystallinity and to investigate thermal stability.

As seen from Figure $2 \mathrm{~h}$, heat treatment at $200{ }^{\circ} \mathrm{C}$ does not influence the intensity of XRD lines and their position, whereas annealing at $300{ }^{\circ} \mathrm{C}$ gives rise to formation of $\mathrm{Bi}_{2} \mathrm{~S}_{3}$ crystalline phase. After annealing at $400{ }^{\circ} \mathrm{C}$, elemental bismuth and bismuth oxysulfide $\mathrm{Bi}_{2} \mathrm{O}_{2} \mathrm{~S}$ are registered along with $\mathrm{Bi}_{10} \mathrm{O}_{6} \mathrm{~S}_{9}$ and $\mathrm{Bi}_{2} \mathrm{~S}_{3}$. Formation of $\mathrm{Bi}^{0}$ seems to be due to $\mathrm{Bi}^{3+}$ reduction by $\mathrm{S}^{2-}$ anions. Heat treatment at $500{ }^{\circ} \mathrm{C}$ leads to the destruction of oxysulfides and their conversion to oxide $\mathrm{Bi}_{2} \mathrm{O}_{3}$ and oxysulfate $\mathrm{Bi}_{2} \mathrm{O}\left(\mathrm{SO}_{4}\right)_{2}$.

The thermogravimetric analysis (TGA) and differential thermal analysis (DTA) curves of bismuth oxysulfide sample from room temperature to $1000{ }^{\circ} \mathrm{C}$ under argon are shown in Figure S5 in Supporting Information. It is observed from the TGA that the weight loss $(2.7 \mathrm{wt} \%)$ at $30-100{ }^{\circ} \mathrm{C}$ is related to the elimination of the physisorbed water, and then up to $340{ }^{\circ} \mathrm{C}$ (3.5 wt\%) to the volatilization of organic residues. Sharp weight loss at $400-490{ }^{\circ} \mathrm{C}(6.9 \mathrm{wt} \%)$ can be attributed to partial loss of sulfur and solid-state transformations including a formation of new bismuth oxysulfide and sulfide phases. This observation can be confirmed by DTA that gives a broad split exothermic peak (at $469,486{ }^{\circ} \mathrm{C}$ ) corresponding to the formation of elemental bismuth and bismuth oxysulfide $\mathrm{Bi}_{2} \mathrm{O}_{2} \mathrm{~S}$ (registered along 
with $\mathrm{Bi}_{10} \mathrm{O}_{6} \mathrm{~S}_{9}$ and $\mathrm{Bi}_{2} \mathrm{~S}_{3}$ ) accordingly XRD data. Weight loss at $800-1000{ }^{\circ} \mathrm{C}$ is associated with oxygen and sulfur elimination from bismuth oxide, oxysulfate, and oxysulfides.

The synthesized bismuth oxysulfide films absorb visible light well (Figure S6, Supporting Information) and demonstrate cathodic photopotential revealing properties of a n-type semiconductor similar to $\mathrm{Bi}_{2} \mathrm{~S}_{3}{ }^{[30]}$ and $\mathrm{Bi}_{2} \mathrm{O}_{2} \mathrm{~S}^{[16]}$ Both anodic and cathodic photocurrents can be generated depending on the electrode potential (Figure 1b). The most prominent property in photoelectrochemical behavior of the synthesized films is extremely high value of cathodic photocurrent in solutions containing electron acceptors (for example, $\left[\mathrm{Fe}(\mathrm{CN})_{6}\right]^{3-}$ ), which corresponds to IPCE up to $2500 \%$ (Figure 1). The cathodic photocurrent increases with cathodic polarization being comparable to the dark current in the entire range of electrode potentials. It should be noted that the giant IPCE effect in $0.5 \mathrm{M} \mathrm{K}_{3}\left[\mathrm{Fe}(\mathrm{CN})_{6}\right]$ solution is rather stable: on the same electrode we have observed giant photocurrents in photoelectrochemical experiments periodically performed throughout the year.

The giant IPCE remains the same for films heat treated at $200{ }^{\circ} \mathrm{C}$, but disappears after heat treatment performed at higher

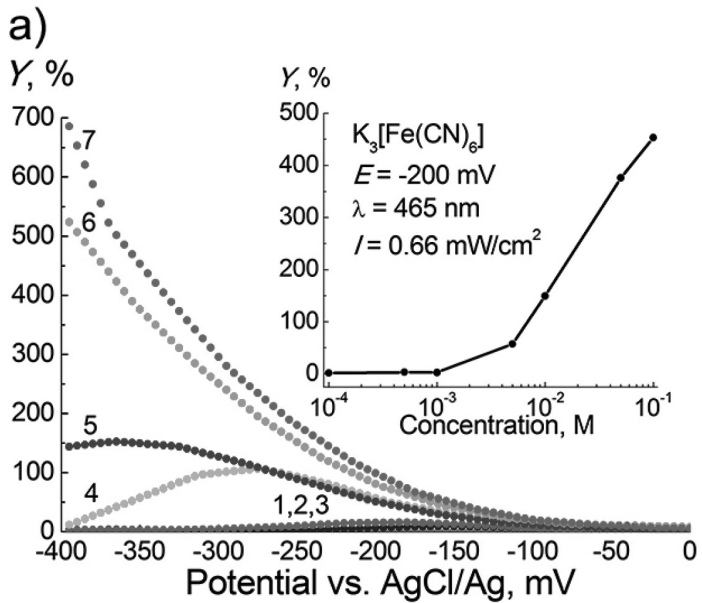

c)

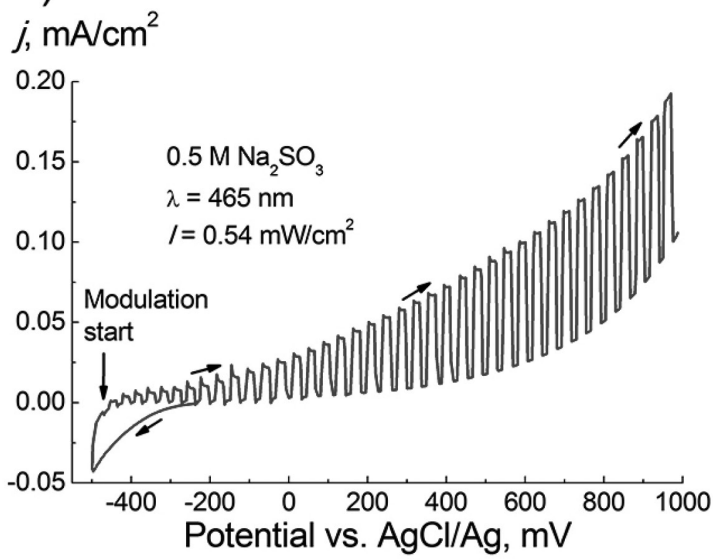

temperatures correlating with changes in phase composition of the films (Figure $2 \mathrm{~h}$ ).

The IPCE value for the cathodic photocurrent depends significantly on the $\left[\mathrm{Fe}(\mathrm{CN})_{6}\right]^{3-}$ concentration in solution and exceeds $100 \%$ only for oxidizer concentration $c>10^{-3} \mathrm{M}$ (Figure 3a). The IPCE decreases with the light intensity increase (Figure 3b) demonstrating a power-like dependence of photocurrent on illumination intensity $j_{\mathrm{ph}} \sim I^{\mathrm{s}}$, with an exponent $s \approx 0.7$.

The giant IPCE is observed not only in $\left[\mathrm{Fe}(\mathrm{CN})_{6}\right]^{3-}$ solutions, but also in electrolytes containing other photoelectron acceptors: $\mathrm{Fe}^{3+}, \mathrm{I}_{3}^{-}, \mathrm{H}_{2} \mathrm{O}_{2}$, quinone (Figure S7, Supporting Information). Strong concentration dependence of the photocurrent testifies that an effective capture of photoelectrons at the semiconductor/electrolyte interface is required for giant IPCE observation.

Only anodic photocurrent is observed for bismuth oxysulfide electrodes in the absence of photoelectron acceptors in the solution. The prepared bismuth oxysulfide films generate an anodic photocurrent in aqueous $\mathrm{Na}_{2} \mathrm{SO}_{3}$ solution (Figure 3c) and in solutions, which contain other acceptors of photoholes, for example, hydroquinone, $\mathrm{Fe}^{2+},\left[\mathrm{Fe}(\mathrm{CN})_{6}\right]^{4-}$. Photoelectrochemical

b)

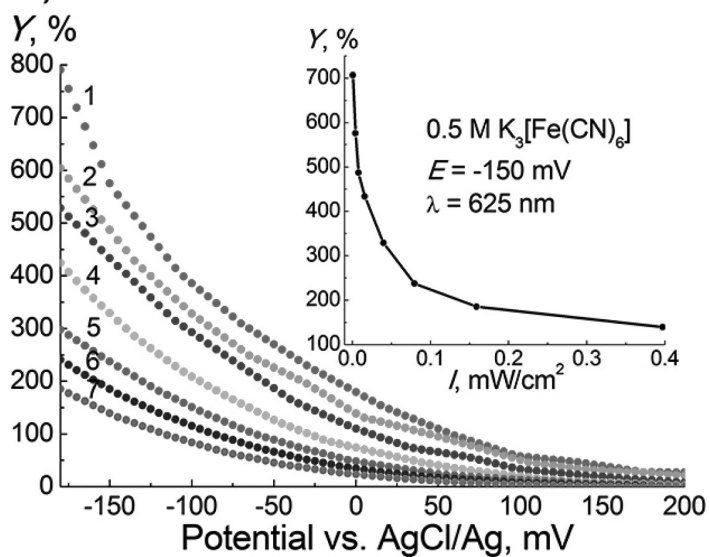

d)

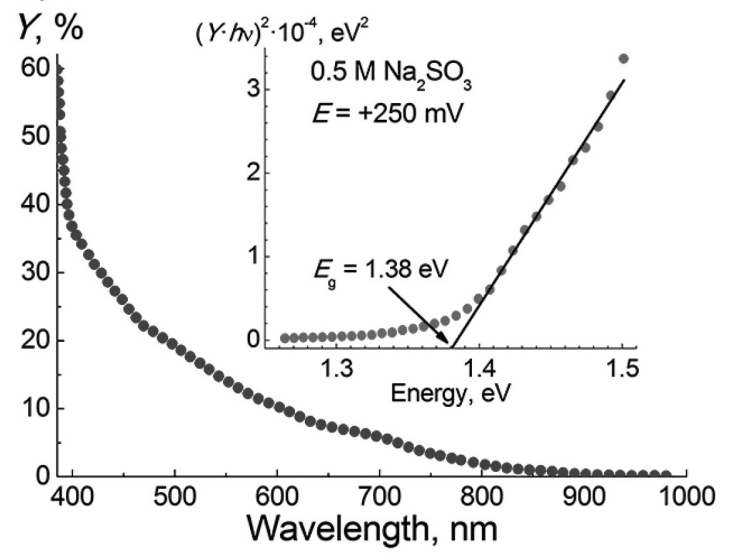

Figure 3. Photoelectrochemical behavior of bismuth oxysulfide films: a) dependence of IPCE for cathodic photocurrent on electrode potential at different concentrations of $\left.\mathrm{K}_{3}\left[\mathrm{Fe}(\mathrm{CN})_{6}\right]: 1-1 \times 10^{-4} \mathrm{M} ; 2-5 \times 10^{-4} \mathrm{M} ; 3-1 \times 10^{-3} \mathrm{M} ; 4-5 \times 10^{-3} \mathrm{M} ; 5-1 \times 10^{-2} \mathrm{M} ; 6-5 \times 10^{-2} \mathrm{M} ; 7-1 \times 10^{-1} \mathrm{M} ; \mathrm{b}\right)$ dependence of IPCE for cathodic photocurrent on electrode potential at different illumination intensities, $\mathrm{mW} \mathrm{cm} \mathrm{cm}^{-2}$ : 1-0.004, 2-0.008, 3-0.016, 4-0.04, 5-0.08, $6-0.16,7-0.40$; c) cyclic voltammogram in $\mathrm{Na}_{2} \mathrm{SO}_{3}$ solution under chopped illumination during anodic scan; d) spectral dependence of IPCE for anodic photocurrent; inset: the same in the Tauc coordinates for direct optical transitions. 
activity of the bismuth oxysulfide films in anodic processes is also high: the IPCE reaches $\approx 40 \%$ in $\mathrm{Na}_{2} \mathrm{SO}_{3}$ solution at $\lambda=400$ $\mathrm{nm}$ (Figure 3d). Extrapolation of anodic photocurrent spectra linearized in $(Y \cdot h v)^{2}-h v$ coordinates (direct optical transitions) demonstrates a band gap energy of bismuth oxysulfide equal to $1.38 \mathrm{eV}$ (Figure 3d, inset). It should be noted that determination of $E_{\mathrm{g}}$ from IPCE (not absorption) spectra seems to be more reliable due to minimal impact of other absorption mechanisms besides the fundamental interband transitions.

To obtain additional information about photoelectrical properties of the prepared films, solid-state measurements were also performed. A thin Au layer was sputtered on the bismuth oxysulfide film grown on FTO glass substrate. It allowed a current flow through the film in direction normal to its plane.

The FTO/ $\mathrm{Bi}_{10} \mathrm{O}_{6} \mathrm{~S}_{9} / \mathrm{Au}$ structure exhibits a long-time persistent photoconductivity (Figure S8, Supporting Information). We have found that the growth and decay of the conductivity after light switching-on and switching-off, respectively, are described well by stretched exponential functions

$$
\begin{aligned}
& \sigma_{g r}(t)=\sigma_{01}+\Delta \sigma_{1}\left[1-\exp \left(-\left(\frac{t}{\tau_{1}}\right)^{\beta_{1}}\right)\right] \\
& \sigma_{d e c}(t)=\sigma_{02}+\Delta \sigma_{2} \exp \left(-\left(\frac{t}{\tau_{2}}\right)^{\beta_{2}}\right)
\end{aligned}
$$

where $\tau_{1}=1.07 \times 10^{3} \mathrm{~s}, \tau_{2}=6.84 \times 10^{3} \mathrm{~s}, \beta_{1}=0.71$, and $\beta_{2}=0.7$. Such long-time relaxations of conductivity are known to be inherent to highly disordered semiconductors and are determined by a wide distribution of parameters of deep charge traps within a forbidden gap. ${ }^{[31]}$

To explain the observed anomalous photoelectrochemical behavior of the prepared films, one should take into account that the electrode resistance is the primary factor limiting the current under cathodic polarization of n-type semiconductor in electrolyte with sufficiently high oxidizer concentration. In this case, the photocurrent arising under illumination is related to decrease in semiconductor resistivity (Figure 4) and is described by the well-known expression (the case of low absorption is considered for simplicity) ${ }^{[32]}$

$$
j_{\mathrm{ph}}=\frac{U}{l} q_{\mathrm{e}} \frac{I \alpha}{h v}\left(\tau_{\mathrm{n}} \mu_{\mathrm{n}}+\tau_{\mathrm{p}} \mu_{\mathrm{p}}\right)
$$

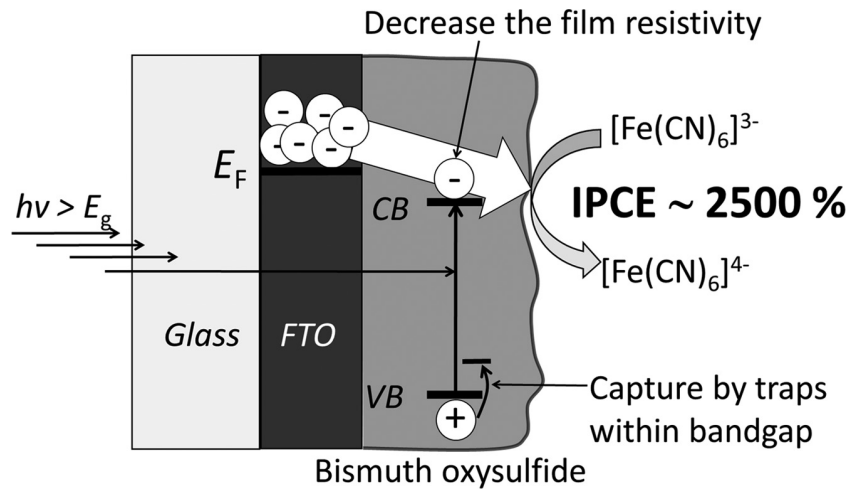

Figure 4. Sketch of giant IPCE effect. where $j_{\mathrm{ph}}$ is the difference between current density under illumination and in dark (i.e., the photocurrent density), $U$ is the voltage drop across semiconductor, $l$ is the interprobe distance, $q_{\mathrm{e}}$ is the electron charge, $I$ is the illumination intensity, $\alpha$ is the light absorption coefficient, $h v$ is the quantum energy, and $\tau_{\mathrm{n}}$, $\tau_{\mathrm{p}}, \mu_{\mathrm{n}}, \mu_{\mathrm{p}}$ are the lifetimes and mobilities of electrons and holes, respectively.

Equation (2) demonstrates no limitations in quantum efficiency values; in other words, the number of electrons passing in the external circuit can exceed the number of incident quanta in many times (photoconductivity gain). At a moderate conductivity of the semiconductor, the main drop of electrode potential in this photoelectrochemical system occurs within the film (potential drop in the Helmholtz layer is insignificant). Increase in cathodic polarization gives rise to the growth of electric field strength in the film (multiplier $U / l$ in Equation (2)) and, hence, to IPCE increase in agreement with experimental results (Figure 1a).

According to Equation (2), high photocurrent can be achieved in the case of a large lifetime of charge carriers. Such situation takes place in semiconductors with high density of defects, which act as traps for the carriers of particular sign and prevent their recombination with the carriers of opposite sign. ${ }^{[33]}$ For example, high photoconductivity of nanocrystalline $\mathrm{Bi}_{2} \mathrm{~S}_{3}$ has been explained taking into account the capture of photoholes by the traps in the forbidden gap. ${ }^{[1]}$ Apparently, a similar situation occurs in the layered oxysulfide crystals. A large concentration of traps in the studied films is in a qualitative agreement with their persistent photoconductivity.

Equation (2) could also explain the observed decrease of quantum efficiency with illumination increase (Figure 3b). Indeed, the lifetime of nonequilibrium charge carriers is independent of the illumination intensity only at low excitation level (when the concentration of the photoexcited charges is much smaller compared with the equilibrium charge concentration) and decreases with the increase of excitation level. Another possible reason of IPCE decrease with the increase of optical power density can be related to the trap filling, which promotes recombination.

As is seen from Figure 3a, giant IPCE values for cathodic current cannot be achieved at low oxidizer concentrations. Therefore, the rate of the photoelectrochemical process (expressed in the terms of cathodic photocurrent density) is determined not only by the concentration of photogenerated carriers, but also, to a large extent, by parameters of the double electric layer, where discharge of electroactive species takes place. A combination of these factors determines the overvoltage of the photoelectrochemical process, which has a pronounced diffusive nature at low oxidizer concentrations.

In summary, it is discovered that the nanolayered bismuth oxysulfide films synthesized by CBD reveal unique-not shown for any known photoelectrochemical systems-properties demonstrating a giant IPCE. For cathodic photocurrent (photoreduction process), the IPCE reaches about 2500\% in aqueous solutions containing electron acceptors $\left(\left[\mathrm{Fe}(\mathrm{CN})_{6}\right]^{3-}\right.$, $\mathrm{Fe}^{3+}, \mathrm{I}_{3}^{-}$, quinone, $\mathrm{H}_{2} \mathrm{O}_{2}$ ). A giant IPCE is observed starting from a certain minimal oxidizer concentration $\left(c>10^{-3} \mathrm{M}\right.$ for $\left.\left[\mathrm{Fe}(\mathrm{CN})_{6}\right]^{3-}\right)$ and decreases nonlinearly with the increase of illumination intensity. Giant IPCE is determined by the decrease 
in resistivity of the bismuth oxysulfide film under illumination, which provides the possibility of charge carriers from external circuit to participate in the photoreduction process (Figure 4). Abnormally high photoelectrochemical activity as well as a band gap energy value favorable for efficient conversion of solar light $(1.38 \mathrm{eV})$ assures that oxysulfide photoelectrodes will form the basis of a new generation of high-performance photoelectrochemical solar cells and photodetectors.

\section{Supporting Information}

Supporting Information is available from the Wiley Online Library or from the author.

\section{Acknowledgements}

The authors thank L. Ivashkevich and N. Brezhneva from Chemical Department of Belarusian State University for the help with samples characterization. E.V.S. thanks RSCF grant no. 17-79-20186 for support. E.A.B., E.A.S., M.V.M., and A.V.M. acknowledge financial support by the Research Program "Photonics, Opto-, and Microelectronics" of the Republic of Belarus.

\section{Conflict of Interest}

The authors declare no conflict of interest.

\section{Keywords}

bismuth oxysulfide, photoconductivity gain, photoelectrochemistry, semiconductors

Received: April 28, 2017 Revised: June 26, 2017

Published online:

[1] Z.-F. Huang, L. Pan, J.-J. Zou, X. Zhang, L. Wang, Nanoscale 2014, 6, 14044.

[2] J. Yu, A. Kudo, Adv. Funct. Mater. 2006, 16, 2163.

[3] Y. Park, K. J. McDonald, K.-S. Choi, Chem. Soc. Rev. 2013, 42, 2321.

[4] J. K. Cooper, S. Gul, F. M. Toma, L. Chen, Y.-S. Liu, J. Guo, J. W. Ager, J. Yano, I. D. Sharp, J. Phys. Chem. C 2015, 119, 2969.

[5] T. W. Kim, K.-S. Choi, Science 2014, 343, 990.
[6] S. K. Poznyak, A. I. Kulak, Electrochim. Acta 1990, 35, 1941.

[7] J. Li, Y. Yu, L. Zhang, Nanoscale 2014, 6, 8473.

[8] H. Cheng, B. Huang, Y. Dai, Nanoscale 2014, 6, 2009.

[9] D. S. Bhachu, S. J. A. Moniz, S. Sathasivam, D. O. Scanlon, A. Walsh, S. M. Bawaked, M. Mokhtar, A. Y. Obaid, I. P. Parkin, J. Tang, C. J. Carmalt, Chem. Sci. 2016, 7, 4832.

[10] M. E. Kazyrevich, M. V. Malashchonak, A. V. Mazanik, E. A. Streltsov, A. I. Kulak, C. Bhattacharya, Electrochim. Acta 2016, 190, 612.

[11] G. Konstantatos, L. Levina, J. Tang, E. H. Sargent, Nano Lett. 2008, 8, 4002.

[12] Y.-C. Lin, M.-W. Lee, J. Electrochem. Soc. 2014, 161, H1.

[13] V. Stavila, K. H. Whitmire, I. Rusakova, Chem. Mater. 2009, 21, 5456.

[14] X. S. Peng, G. W. Meng, J. Zhang, L. X. Zhao, X. F. Wang, Y. W. Wang, L. D. Zhang, J. Phys. D: Appl. Phys. 2001, 34, 3224.

[15] P. Han, A. Mihi, J. Ferre-borrull, J. Pallarés, L. F. Marsal, J. Phys. Chem. C 2015, 119, 10693.

[16] A. L. Pacquette, H. Hagiwara, T. Ishihara, A. A. Gewirth, J. Photochem. Photobiol., A 2014, 277, 27.

[17] X. Zhang, Y. Liu, G. Zhang, Y. Wang, H. Zhang, F. Huang, ACS Appl. Mater. Interfaces 2015, 7, 4442.

[18] S. Meng, X. Zhang, G. Zhang, Y. Wang, H. Zhang, F. Huang, Inorg. Chem. 2015, 54, 5768.

[19] A. Miura, Y. Mizuguchi, T. Takei, N. Kumada, E. Magome, C. Moriyoshi, Y. Kuroiwa, K. Tadanaga, Solid State Commun. 2016, 227, 19.

[20] O. Madelung, Semiconductors: Data Handbook, Springer-Verlag, Berlin, Germany 2004

[21] Y. Mizuguchi, H. Fujihisa, Y. Gotoh, K. Suzuki, H. Usui, K. Kuroki, S. Demura, Y. Takano, H. Izawa, O. Miura, Phys. Rev. B 2012, 86, 220510(R).

[22] W. A. Phelan, D. C. Wallace, K. E. Arpino, J. R. Neilson, K. J. Livi, C. R. Seabourne, A. J. Scott, T. M. McQueen, J. Am. Chem. Soc. 2013, 135, 5372

[23] G. Liu, D. Li, S. Li, J. Wang, W. liu, Z. Zhang, Physica C 2015, 510, 27.

[24] S. Nambiar, E. K. Osei, J. T. W. Yeow, Sci. Rep. 2015, 5, 9440.

[25] A. Intaniwet, C. A. Mills, M. Shkunov, P. J. Sellin, J. L. Keddie, Nanotechnology 2012, 23, 235502.

[26] E. Koyama, I. Nakai, K. Nagashima, Acta Crystallogr. 1984, B40, 105.

[27] S. Gaponenko, H. V. Demir, C. Seassal, U. Woggon, Opt. Express 2016, 24, A430.

[28] T. P. Debies, J. W. Rabalais, Chem. Phys. 1977, 20, 277.

[29] J. Watts, J. Wolstenholme, An Introduction to Surface Analysis by XPS and AES, John Wiley \& Sons Ltd., Chichester, England 2008.

[30] R. N. Bhattacharya, P. Pramanik, J. Electrochem. Soc. 1982, 129, 332.

[31] Y. Tian, C.F. Guo, J. Zhang, Q. Liu, Phys. Chem. Chem. Phys. 2015, $17,851$.

[32] R. H. Bube, Photoconductivity of Solids, Wiley, New York, NY 1960.

[33] D. V. Talapin, J. S. Lee, M. V. Kovalenko, E. V. Shevchenko, Chem. Rev. 2010, 110,389. 